\title{
Neural correlates of cognitive intervention in persons at risk of developing Alzheimer's disease
}

\author{
S. M. Hadi Hosseini ${ }^{1}{ }^{*}$, Joel H. Kramer ${ }^{2}$ and Shelli R. Kesler ${ }^{1,3}$ \\ 1 Department of Psychiatry and Behavioral Sciences, Stanford University School of Medicine, Stanford, CA, USA \\ ${ }^{2}$ Department of Neurology, Memory and Aging Center, University of California, San Francisco, CA, USA \\ ${ }^{3}$ Stanford Cancer Institute, Palo Alto, CA, USA
}

\section{Edited by:}

Rommy Von Bernhardi, Pontificia

Universidad Católica de Chile, Chile

\section{Reviewed by:}

Donald G. McLaren, Massachusetts General Hospital, USA

Jan Laczó, Charles University in

Prague, Czech Republic

${ }^{*}$ Correspondence:

S. M. Hadi Hosseini, Department of Psychiatry and Behavioral Sciences, Stanford University School of

Medicine, 401 Quarry Rd., Stanford, CA 94305-5795, USA

e-mail: hosseiny@stanford.edu;

hadi.hosseini@gmail.com
Cognitive training is an emergent approach that has begun to receive increased attention in recent years as a non-pharmacological, cost-effective intervention for Alzheimer's disease (AD). There has been increasing behavioral evidence regarding training-related improvement in cognitive performance in early stages of AD. Although these studies provide important insight about the efficacy of cognitive training, neuroimaging studies are crucial to pinpoint changes in brain structure and function associated with training and to examine their overlap with pathology in AD. In this study, we reviewed the existing neuroimaging studies on cognitive training in persons at risk of developing $A D$ to provide an overview of the overlap between neural networks rehabilitated by the current training methods and those affected in AD. The data suggest a consistent training-related increase in brain activity in medial temporal, prefrontal, and posterior default mode networks, as well as increase in gray matter structure in frontoparietal and entorhinal regions. This pattern differs from the observed pattern in healthy older adults that shows a combination of increased and decreased activity in response to training. Detailed investigation of the data suggests that training in persons at risk of developing AD mainly improves compensatory mechanisms and partly restores the affected functions. While current neuroimaging studies are quite helpful in identifying the mechanisms underlying cognitive training, the data calls for future multi-modal neuroimaging studies with focus on multi-domain cognitive training, network level connectivity, and individual differences in response to training.

Keywords: cognitive training, mild cognitive impairment (MCl), aging, plasticity, neuroimaging, cognitive stimulation, computerized training

\section{INTRODUCTION}

Alzheimer's disease $(\mathrm{AD})$ is the most common form of dementia, a general term for memory loss and other intellectual abilities serious enough to interfere with daily life. Recent World Alzheimer's Report indicates that over 35 million people worldwide have $\mathrm{AD}$ in 2013 and this number is expected to triple by 2050 (Prince et al., 2013). Alzheimer's is not solely a cognitive problem. In the United States, $\mathrm{AD}$ is the sixth leading cause of death across all ages (Murphy et al., 2013) and over 500,000 deaths annually may be attributable to $\mathrm{AD}$ in older adults aged 75 years and older in 2010 (James et al., 2014). While it has been more than 100 years since $\mathrm{AD}$ was first identified, there are still no effective disease-modifying drugs available for this (Buschert et al., 2010). The number of mortalities attributed to $\mathrm{AD}$ is still increasing while the number of deaths attributed to other fatal diseases (heart disease, cancer, and stroke) has decreased (Murphy et al., 2013), calling for development of new cost-effective treatments.

Cognitive training is a guided practice on a set of standard tasks designed to increase particular cognitive functions that further supports accomplishments of everyday tasks and independent living (Lindesay et al., 2010; Rebok et al., 2014). It has been shown that cognitive training promotes several neuroplastic mechanisms in the brain that can be conserved well into advanced age (Nyberg et al., 2003; Boyke et al., 2008; de Villers-Sidani et al., 2010). Candidate cellular mechanisms underlying gray matter plasticity include axon sprouting, dendritic branching and synaptogenesis, neurogenesis and glial changes whereas the mechanisms underlying white matter changes include myelination, changes in fiber organization, astrocyte changes and angiogenesis (Zatorre et al., 2012). Thus, cognitive training has begun to receive increased attention in recent years as a non-pharmacological, cost-effective intervention and treatment of AD.

There has been increasing behavioral evidence demonstrating training-related improvement in cognitive performance in early stages of AD (Cipriani et al., 2006; Barnes et al., 2009; Kinsella et al., 2009; Li et al., 2011; Gagnon and Belleville, 2012; Herrera et al., 2012; Moro et al., 2012; Rovner et al., 2012; Valdes et al., 2012; Gaitán et al., 2013; Greenaway et al., 2013; Reijnders et al., 2013). While these studies provide important insight about the 
efficacy of cognitive training, neuroimaging studies are crucial to pinpoint changes in brain structure and function associated with cognitive training. Previous reviews on neuropathology of $\mathrm{AD}$ suggest distributed changes in brain structure and function comprising temporal, frontoparietal, and default mode networks (Buckner et al., 2005; Bokde et al., 2009; Seeley et al., 2009; Browndyke et al., 2013; Radanovic et al., 2013). These widespread neuronal changes suggest the importance of neuroimaging studies to investigate the overlap between neural networks rehabilitated by the training procedure and those affected in $\mathrm{AD}$.

Moreover, multi-modal neuroimaging studies can further our understanding of neuroanatomical and functional mechanisms underlying cognitive training. Specifically, cognitive training can result in improved performance in various ways: training might result in rehabilitation (or normalization) of the affected structure (or function) and/or reorganization of alternate networks to compensate for the role of the affected regions (Kelly et al., 2006a). Training programs must ideally favor the rehabilitation/normalization mechanisms and ensure that the compensatory mechanisms do not negatively impact the intact functions through sharing resources (Behrmann et al., 2005). Understanding the training-related mechanisms is crucial to design efficient and effective cognitive training programs for treatment/intervention of AD.

In this review article, we provide an overview of the functional and structural neuroimaging studies on cognitive training in normal aging and persons at risk of developing $\mathrm{AD}$ to identify the potential mechanisms underlying current cognitive training procedures. We will then discuss the limitations of the current studies and address the implications of the findings for future research.

\section{FUNCTIONAL AND STRUCTURAL PLASTICITY IN OLD AGE}

Recent findings suggest that cognitive training results in neuroanatomical and functional changes that extend into advanced age. Nyberg et al. (2003) were among the first to show changes in occipito-parietal activity in older adults who benefited from memory training using O-15 $\mathrm{H}_{2} \mathrm{O}$ PET. Since then, several functional MRI and PET studies have shown training-related changes in brain activity in healthy older adults [see Belleville and Bherer, 2012 for a review]. It has been shown that cognitive training can reduce age differences in ventral and dorsal prefrontal activation (Erickson et al., 2007) and decrease neocortical brain activity observed with functional MRI (Brehmer et al., 2011), and increase resting cerebral blood flow to the default-mode network and central executive network observed with perfusion MRI (Mozolic et al., 2010; Chapman et al., 2013) in older adults. These findings provide evidence for functional plasticity in old age and suggest a mixed pattern of increased and decreased activation in response to training in healthy older adults.

Evidence regarding training-related structural plasticity in old age is more recent. Boyke et al.'s (2008) study was one of the earliest successful attempts that showed increased gray-matter volume in the middle temporal regions in older adults after 3 months of training on a three-ball cascade juggling. Recent studies have repeatedly demonstrated structural plasticity associated with cognitive training in healthy older adults. Cognitive training resulted in increased thickness in the right insula, left lateral orbitofrontal and fusiform cortices (Engvig et al., 2010), stabilized hippocampal volume (Lövdén et al., 2012), increased fractional anisotropy (FA) and decreased mean diffusivity (MD) in the genu of corpus callosum (Lövdén et al., 2010; Engvig et al., 2012a), and increased FA in the frontal white matter tracts (Engvig et al., 2012a) in response to training. These data support experience-dependent plasticity of gray and white matter structure in advanced age. Unlike the mixed pattern of changes in functional plasticity, structural changes consistently show an increased pattern (or reduced age-related decline). The above functional and structural neuroimaging evidence suggest that cognitive training can be employed to restore neuroanatomical decline associated with aging.

\section{PATTERN OF TRAINING-RELATED CHANGES IN BRAIN FUNCTION AND STRUCTURE IN PERSONS AT RISK OF AD}

There have been a few efforts to examine changes in brain function and structure in response to cognitive training in $\mathrm{AD}$. Most of these studies focus on older adults with mild cognitive impairment (MCI), a risk factor for developing dementia. We summarized the results of functional MRI studies that investigated the effect of cognitive training in persons at risk of developing $\mathrm{AD}$ (Table 1). We searched PubMed for the keywords "Alzheimer's disease" or "MCI" or "Mild Cognitive Impairment", and "Cognitive Intervention" or "Cognitive Training" or "Cognitive Stimulation", and "functional MRI" or "fMRI" or "PET" or "Positron Emission Tomography" or "EEG" or "Electroencephalography" or "MEG" or "Magnetoencephalography" or "Brain". Only studies that examined the effect of training on brain function using functional MRI were included in the summary, since we could not aggregate the results of EEG/MEG and PET studies with fMRI. However, the corresponding results

Table 1 | The list of the included functional MRI studies.

\begin{tabular}{|c|c|c|c|c|c|}
\hline Study & Cognitive training & Target & Control & Duration & fMRI task \\
\hline Belleville et al. (2011) & Memory training & $\mathrm{MCl}$ & HC-active & $6 w$ & Face-name assoc. (memory) \\
\hline Carlson et al. (2009) & Experience corps & $\mathrm{MCl}$ & MCl-waitlist & $6 \mathrm{~m}$ & Flanker (executive function) \\
\hline Hampstead et al. (2011) & Memory training & $\mathrm{MCl}$ & $\mathrm{MCl}^{*}$ & $2 w$ & Face-name assoc. (memory) \\
\hline Hampstead et al. (2012) & Memory training & $\mathrm{MCl}$ & HC-active & $2 w$ & Face-name assoc. (memory) \\
\hline Rosen et al. (2011) & Auditory processing & $\mathrm{MCl}$ & MCl-active & $2 \mathrm{~m}$ & Auditory-verbal (memory) \\
\hline
\end{tabular}

w: weeks; m: months; * within-subjects control condition. 
were briefly noted. We did not include case studies in the analysis (Clare et al., 2009; van Paasschen et al., 2009). Non-English, non-human studies were not included. Five studies fulfilled the inclusion criteria (see Table 1 for details). No additional studies were found using other databases (e.g., Web of Science) and search engines (e.g., Google Scholar). Since most of the studies did not report the coordinates of observed changes in brain activity, we could not perform a systematic meta-analysis (e.g., activation likelihood estimation, ALE; Eickhoff et al., 2009). Instead, we assigned the reported regions (or coordinates when they are available) to corresponding region of interest (ROI) in Automated Anatomical Labeling (AAL) atlas (Tzourio-Mazoyer et al., 2002) and summarized the findings based on the frequency of the observed activations in each ROI across studies (Figure 1A). The observed pattern suggests a consistent increase (or attenuated decline) in activity of distributed brain regions, including hippocampal, prefrontal, and posterior default mode network in response to training. These results are corroborated by PET and EEG studies that reported increased metabolic activity and functional plasticity after training in $\mathrm{AD}$ (Forster et al., 2011; Spironelli et al., 2013). It should be noted that the observed pattern of activity is confounded by different types of training programs and outcomes involved in the studies and thus makes it difficult to compare the effect between clinical groups.

Regarding the underlying mechanism, the above studies reported both functional normalization and compensation in response to training. Specifically, restoration of hippocampal activity was reported in several memory-training studies (Rosen et al., 2011; Hampstead et al., 2012). The restoration of activity in task-specific regions was parallel with increased activity in alternative brain regions that were not active at baseline in comparison with controls (Belleville et al., 2011; Hampstead et al., 2011,2012) that suggests compensatory recruitment of alternative networks.

The dominant training-related increase in functional activity in persons at risk of developing AD (Figure 1A) differs from the observed pattern in healthy aging which shows a combination of increase and decrease in activity. It has been shown that changes in brain function antedate the cognitive decline and pathological effects of amyloid deposition in persons at risk of developing AD (Sheline et al., 2010). MCI has been associated with prominent changes in brain function [see Browndyke et al., 2013; Risacher and Saykin, 2013 for a review]. We speculate that the dominant training-related increase in brain activity in MCI subjects signals mainly compensation and partly normalization of the affected functions. On the other hand, in healthy aging, training results in a decrease in the recruitment of compensatory regions (decrease in activity) as well as an increase in brain activity which indicates functional normalization of the regions affected by normal agerelated decline. The latter is supported by the data showing an increase in hemispheric asymmetry in response to training in healthy aging (Erickson et al., 2007). Extended cognitive training in MCI may decrease the activations in the compensatory regions and further restore the function of the regions affected by the disease (Kelly et al., 2006b). Figure 1B illustrates a hypothetical model of the interaction between cognitive training, normal aging, and MCI during task performance. Future studies need to test this model in a controlled study.

To examine the effect of cognitive training on brain structure in $\mathrm{AD}$ and persons at risk of developing $\mathrm{AD}$, we searched PubMed for the keywords "Alzheimer's disease" or "MCI" or "Mild Cognitive Impairment", and "Cognitive Intervention" or "Cognitive Training" or "Cognitive Stimulation", and "structural MRI" or "VBM" or "FreeSurfer" or "Brain". We only found one recent study that reported structural changes associated with cognitive training in older adults with subjective memory impairment (SMI; Engvig et al., 2014). Subjects with SMI are at high risk of developing AD (Jessen et al., 2010). The authors reported increased gray matter volume in the left supramarginal and entorhinal regions and in the right inferior temporal and inferior frontal regions after an 8 -week memory-training program. The restoration of hippocampal structure after training in SMI group was not significant (Engvig et al., 2014). The limited data suggest a reorganization of memory network (increased cortical volume in the prefrontal cortex) in response to training and favors a compensatory mechanism.

Training-related changes in structural plasticity in persons at risk of developing $\mathrm{AD}$ seem to follow the same direction as in healthy aging. However, consistent with our speculation of functional plasticity, it seems that training mainly results in structural plasticity in compensatory regions in at risk subjects while it shows both restorative and compensatory effects in healthy aging. This idea is corroborated by Engvig et al.s (2014) study that showed restoration of hippocampal structure after training in healthy aging group but not in the SMI group. Extended training in persons at risk of developing $\mathrm{AD}$ might result in further restoration of the affected structures.

\section{FUTURE DIRECTIONS}

Recent efforts toward understanding neurocognitive changes associated with cognitive training are promising. However, there are several limitations in the current studies that need to be addressed in the future research. The limitations in the design of the studies, including the lack of active control/placebo group, test-retest reliability of the training outcome, reliability of neuroimaging measures for assessing neuronal change, interaction between the training tasks and outcome measures, compliance, small sample size, lack of effect size information, effects of training on biomarker status (e.g., amyloid deposition), near vs. far transfer and maintenance of gains, have been discussed in previous literature (Clément and Belleville, 2009; van Paasschen et al., 2009; Buschert et al., 2010; Putcha et al., 2011; Belleville and Bherer, 2012; Park and Bischof, 2013). Here we focused on other factors that are critical for understanding the underlying mechanisms of cognitive training.

\section{ASSESSING NETWORK-LEVEL CHANGES ASSOCIATED WITH COGNITIVE TRAINING}

In the last decade, there has been increasing evidence regarding aberrant functional and structural connectivity in various stages of $\mathrm{AD}$ [see He et al., 2009; Filippi and Agosta, 2011; Radanovic et al., 2013 for a review]. Functional connectivity pattern at 
A

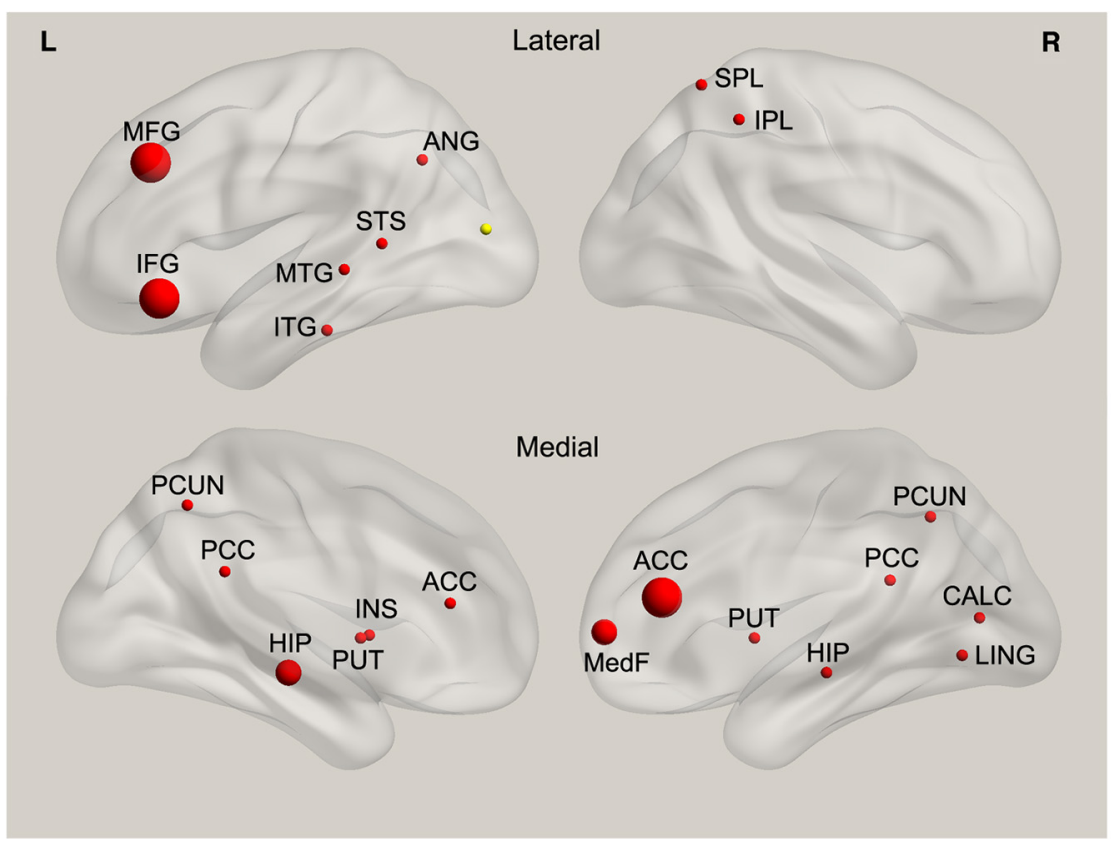

B

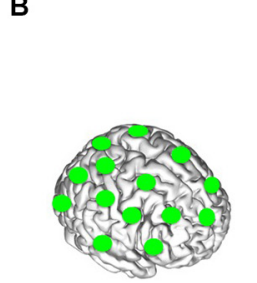

Task-related activation patterm in healthy young adults

\section{Cognitive Intervention}

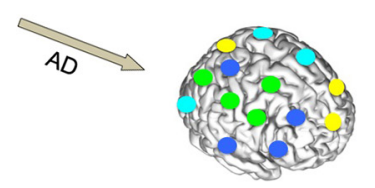

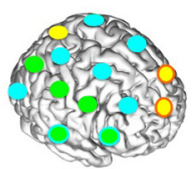
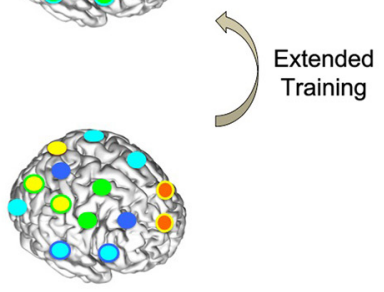

Compensatory

Activation
FIGURE 1 | (A) Effect of cognitive training on functional brain activity in AD. The spheres indicate the regions that showed significant training-related changes in $A D$ compared with controls. The size of the spheres corresponds to the frequency of observed activations across studies. Red (yellow) color indicates training-related increase (decrease) in activity. (B) A conceptual model of the effect of training on task-related functional activity in AD. Left panel: the normal pattern of brain activity during a hypothetical task in healthy young adults (green circles). Middle panel: with normal aging, task performance is associated with a combination of reduced activity in task-specific brain regions (cyan circles) and compensatory activation in the alternate networks (orange and yellow circles). However, compared with healthy aging, $A D$ results in a more pronounced reduction in the activity of some of the task-specific regions (blue circles) and a breakdown of the compensatory network (yellow circles). Right panel: cognitive training in healthy aging leads to normalization of brain activity in some of the task-specific regions (green circles with cyan boundary) as well as reduced compensatory activations (yellow circles with orange boundary). This pattern is consistent with the cognitive training literature showing a combination of training-related increase (normalization) and decrease (less compensation) in activity in healthy aging. On the other hand, training in AD leads to partly restoration of the activity in some of the task-specific regions (cyan circles with blue boundary) parallel with recovery of part of the compensatory network (orange circles with yellow boundary) and recruitment of new compensatory networks (yellow circles with green boundary). This pattern is consistent with the observed dominant increase in brain activity (combination of restoration and compensation) in $A D$ after training. rest-specifically the default-mode network connectivity-has gained a lot of attention in recent years as a promising biomarker for tracking changes in AD progression (Koch et al., 2012; GomezRamirez and $\mathrm{Wu}, 2014)$. It has been shown that alterations in resting-state network-antedate the pathological effects of amyloid plaque toxicity (Sheline et al., 2010). Reduced integrity in the default mode network is also associated with amyloid beta and tau pathology before the clinical onset of AD (Wang et al., 2013). Several pharmacological intervention studies have employed the resting-state connectivity as a biomarker for testing the efficacy of the treatment (Goveas et al., 2011; Lorenzi et al., 2011; Li et al., 2012) [see Hampel et al., 2011 for a related discussion]. Future cognitive training studies need to adopt a similar approach to test the effect of cognitive training on default-mode network. 
With respect to task-related functional connectivity, psychophysiological interactions (PPI) analysis tests task-specific changes in functional connectivity between various brain regions (O'Reilly et al., 2012). Recently, McLaren et al. (2012) proposed the concept of generalized context-dependent PPI (gPPI)with increased flexibility of statistical modeling-that can reveal complementary information regarding subtle within- and between-network interactions and might be more sensitive compared with resting-state connectivity and task-activation methods. Effective connectivity analysis is an alternative approach that tests the influence of a neural system over another and thus takes into account the directionality of the connections (Friston, 2011). These methods can be employed to investigate the effect of training on brain connectivity during task performance.

Coordinated variations in brain morphology (e.g., volume) among different brain regions have been recently employed to infer large-scale structural covariance networks in health and disease (He et al., 2007; Bernhardt et al., 2011; Hosseini and Kesler, 2013; Hosseini et al., 2013; Singh et al., 2013). The co-occurring atrophy in regional volume in the default-mode network and medial temporal structures has been shown to relate to elevated levels of amyloid beta and tau pathology (Carmichael et al., 2012). Other studies reported alterations in the global and regional organization of structural covariance networks associated with MCI and AD (He et al., 2008; Yao et al., 2010). These networks can be used to identify the long-term effects of training on brain networks.

Despite the clear network-level substrate for cognitive deficits in $\mathrm{AD}$, there is only one study that investigated changes in brain connectivity in response to memory training in MCI patients (Hampstead et al., 2011). Using granger causality analysis, Hampstead et al. (2011) found increased effective connectivity in the middle temporal gyrus, precuneus and occipital cortex after training. These findings could help the authors clarify how explicit memory training provides a mechanism to recruit compensatory memory processes mediated by the posterior default mode network. Future studies need to investigate the effects of training on brain connectivity and organization of brain networks in order to dissociate the compensatory and restorative effects of training at network level.

\section{INDIVIDUAL DIFFERENCES IN RESPONSE TO TRAINING}

While causes of AD are yet to be understood, there is an agreement that $\mathrm{AD}$ develops as a result of multiple risk factors. Genetic, demographic and host factors play an important role in $\mathrm{AD}$ development. Presence of APOE- $\varepsilon 4$ allele has been associated with increased rate of cognitive decline and increased neuropathology including greater $\beta$-amyloid deposition and medial temporal lobe atrophy (Ohm et al., 1995; Dal Forno et al., 1996; Geroldi et al., 1999; Martins et al., 2005; Lim et al., 2013). Higher educational attainment has also been associated with reduced risk of $\mathrm{AD}$ in multiple studies (McDowell et al., 2007; Roe et al., 2007; Meng and D'Arcy, 2012) potentially through cognitive reserve mechanism (Stern, 2006; Brayne et al., 2010). The cognitive reserve theory posits that individual differences in brain structure and/or efficiency to information processing provide differential protection against brain pathology or age-related changes (Stern, 2006). Higher educational attainment can thus delay the onset of dementia through mitigating the impact of pathology on the clinical expression of AD (Brayne et al., 2010).

Disease stage and individual differences in the pattern of pathology would also impact the training outcomes. Unfortunately, little information is available on the effect of individual differences on training outcomes. A recent study has tested the effect of individual's hippocampal subfield volume on memory training outcomes in SMI and reported that subjects with larger hippocampal volume at baseline would gain greater improvement in verbal recall after training (Engvig et al., 2012b). Integrative studies need to address the effect of individual differences in genetic and demographic factors on training outcomes that further helps to design efficient cognitive training programs. Specifically, multivariate pattern analysis can be employed to predict with high accuracy how an individual would respond to training using the neuroimaging, genetic and demographic information at baseline. These techniques have been extensively used in neuroimaging literature for predicting disease and/or disease stage (Bray et al., 2009; Hoeft et al., 2011; Orrù et al., 2012). Finally, neuroimaging measures can be employed to identify the brain regions (networks) that are affected by the disease at individual level. In recent years, there has been an increase in the number of studies that compare the single case data against a control group (Rosen et al., 2002; Zahn et al., 2005; Sehm et al., 2011). Although the results of such single-case studies are still controversial (Scarpazza et al., 2013), these studies can be quite helpful to identify the target network for cognitive training and to investigate how the function/structure of those networks are recovered after training. Neurofeedback technology can also be employed to target the identified networks (Koush et al., 2013). These technologies will ultimately lead to customizing cognitive training programs for individuals.

\section{MULTI-DOMAIN COGNITIVE TRAINING}

While most of the neuroimaging studies of cognitive training in $\mathrm{AD}$ have focused on memory training, the results suggest an increased activity and gray matter volume in various prefrontal regions (Figure 1A). Previous neuroimaging studies have indicated the involvement of prefrontal regions in memory formation and suggest that the likelihood of memory formation correlates with the level of activity in prefrontal regions (Buckner et al., 1999; Peleg-Raibstein et al., 2005). Executive functions (EFs), specifically the working memory components, have been shown to exacerbate memory deficits and could represent a critical factor in AD progression (Ranganath et al., 2005; Nagata et al., 2011; Parks et al., 2011; Clément et al., 2013). It has been shown that EF in MCI patients, and not in normal aging, declines faster than memory (Johnson et al., 2012). Functional neuroimaging studies on MCI showed hyper-activation and hypoactivation in prefrontal regions in MCI patients with high and low cognitive functions, respectively (Dannhauser et al., 2005; Yetkin et al., 2006), an observation that suggest a breakdown of executive function network with progression of AD. These data are corroborated by recent evidence that showed impairments in EF even in early stages of AD (Rainville et al., 2012; 
Clément et al., 2013). These data suggest that including training components focused on $\mathrm{EF}$ in the practicum is necessary to restore/normalize the affected structure/function of the prefrontal regions and to further facilitate the recovery of the medial temporal regions. This idea is supported by a recent study that provided behavioral evidence of improvement in memory processes as a result of working memory training (Rudebeck et al., 2012).

Multi-domain cognitive training programs have the potential to maximize the restorative/normalizing effects of training that is the ideal goal of training. Gates et al. reviewed the behavioral effects of cognitive training on normal aging, MCI and dementia and suggested that multi-domain cognitive training has the potential to improve cognitive functions in healthy older adults and slow the cognitive decline in MCI population (Gates and Valenzuela, 2010). Compared with single-domain training, multi-domain cognitive training is more advantageous in terms of training-effect maintenance in non-demented older adults (Cheng et al., 2012). Additionally, parallel practice is believed to improve transfer effects of training to untrained and/or realworld skills (Green and Bavelier, 2008). The effect of multidomain cognitive training on brain structure and function in $\mathrm{AD}$ needs to be investigated in the future studies.

In summary, we reviewed the neuroimaging studies that investigated the effects of cognitive training on brain structure and function in persons at risk of developing AD. Current data suggest that brain structural and functional plasticity advance into old age and that cognitive training can be employed to restore neurocognitive decline associated with AD. Training in persons at risk of developing $\mathrm{AD}$ was associated with increased brain activity and gray matter volume across studies that mainly indicate recruitment of compensatory mechanisms. Future multi-modal neuroimaging studies with focus on training various cognitive domains need to investigate the effect of training on the diffuse pathology associated with AD. Additionally, future neuroimaging research need to examine the individual differences in response to training and clarify the role of genetic and host factors on training outcome.

\section{REFERENCES}

Barnes, D. E., Yaffe, K., Belfor, N., Jagust, W. J., DeCarli, C., Reed, B. R., et al. (2009). Computer-based cognitive training for mild cognitive impairment: results from a pilot randomized, controlled trial. Alzheimer Dis. Assoc. Disord. 23, 205-210. doi: 10.1097/WAD.0b013e31819c6137

Behrmann, M., Marotta, J., Gauthier, I., Tarr, M. J., and McKeeff, T. J. (2005). Behavioral change and its neural correlates in visual agnosia after expertise training. J. Cogn. Neurosci. 17, 554-568. doi: 10.1162/0898929053467613

Belleville, S., and Bherer, L. (2012). Biomarkers of cognitive training effects in aging. Curr. Transl. Geriatr. Exp. Gerontol. Rep. 1, 104-110. doi: 10.1007/s13670012-0014-5

Belleville, S., Clément, F., Mellah, S., Gilbert, B., Fontaine, F., and Gauthier, S. (2011). Training-related brain plasticity in subjects at risk of developing Alzheimer's disease. Brain 134(Pt. 6), 1623-1634. doi: 10.1093/brain/awr037

Bernhardt, B. C., Chen, Z., He, Y., Evans, A. C., and Bernasconi, N. (2011). Graph-theoretical analysis reveals disrupted small-world organization of cortical thickness correlation networks in temporal lobe epilepsy. Cereb. Cortex 21, 2147-2157. doi: 10.1093/cercor/bhq291

Bokde, A. L., Ewers, M., and Hampel, H. (2009). Assessing neuronal networks: understanding Alzheimer's disease. Prog. Neurobiol. 89, 125-133. doi: 10.1016/j. pneurobio.2009.06.004
Boyke, J., Driemeyer, J., Gaser, C., Buchel, C., and May, A. (2008). Training-induced brain structure changes in the elderly. J. Neurosci. 28, 7031-7035. doi: 10. 1523/JNEUROSCI.0742-08.2008

Bray, S., Chang, C., and Hoeft, F. (2009). Applications of multivariate pattern classification analyses in developmental neuroimaging of healthy and clinical populations. Front. Hum. Neurosci. 3:32. doi: 10.3389/neuro.09.032.2009

Brayne, C., Ince, P. G., Keage, H. A., McKeith, I. G., Matthews, F. E., Polvikoski, T., et al. (2010). Education, the brain and dementia: neuroprotection or compensation? Brain 133(Pt. 8), 2210-2216. doi: 10.1093/brain/awq185

Brehmer, Y., Rieckmann, A., Bellander, M., Westerberg, H., Fischer, H., and Backman, L. (2011). Neural correlates of training-related working-memory gains in old age. Neuroimage 58, 1110-1120. doi: 10.1016/j.neuroimage.2011. 06.079

Browndyke, J. N., Giovanello, K., Petrella, J., Hayden, K., Chiba-Falek, O., Tucker, K. A., et al. (2013). Phenotypic regional functional imaging patterns during memory encoding in mild cognitive impairment and Alzheimer's disease. Alzheimers Dement. 9, 284-294. doi: 10.1016/j.jalz.2011.12.006

Buckner, R. L., Kelley, W. M., and Petersen, S. E. (1999). Frontal cortex contributes to human memory formation. Nat. Neurosci. 2, 311-314. doi: 10.1038/7221

Buckner, R. L., Snyder, A. Z., Shannon, B. J., LaRossa, G., Sachs, R., Fotenos, A. F., et al. (2005). Molecular, structural and functional characterization of Alzheimer's disease: evidence for a relationship between default activity, amyloid and memory. J. Neurosci. 25, 7709-7717. doi: 10.1523/jneurosci.2177-05. 2005

Buschert, V., Bokde, A. L., and Hampel, H. (2010). Cognitive intervention in Alzheimer disease. Nat. Rev. Neurol. 6, 508-517. doi: 10.1038/nrneurol.2010.113

Carlson, M. C., Erickson, K. I., Kramer, A. F., Voss, M. W., Bolea, N., Mielke, M., et al. (2009). Evidence for neurocognitive plasticity in at-risk older adults: the experience corps program. J. Gerontol. A Biol. Sci. Med. Sci. 64, 1275-1282. doi: 10.1093/gerona/glp117

Carmichael, O., McLaren, D. G., Tommet, D., Mungas, D., Jones, R. N., and for the Alzheimer's Disease Neuroimaging Initiative. (2012). Coevolution of brain structures in amnestic mild cognitive impairment. Neuroimage 66C, 449-456. doi: 10.1016/j.neuroimage.2012.10.029

Chapman, S. B., Aslan, S., Spence, J. S., Hart, J. J. J., Bartz, E. K., Didehbani, N., et al. (2013). Neural mechanisms of brain plasticity with complex cognitive training in healthy seniors. Cereb. Cortex doi: 10.1093/cercor/bht234. [Epub ahead of print].

Cheng, Y., Wu, W., Feng, W., Wang, J., Chen, Y., Shen, Y., et al. (2012). The effects of multi-domain versus single-domain cognitive training in non-demented older people: a randomized controlled trial. BMC Med. 10:30. doi: 10.1186/17417015-10-30

Cipriani, G., Bianchetti, A., and Trabucchi, M. (2006). Outcomes of a computerbased cognitive rehabilitation program on Alzheimer's disease patients compared with those on patients affected by mild cognitive impairment. Arch. Gerontol. Geriatr. 43, 327-335. doi: 10.1016/j.archger.2005.12.003

Clare, L., van Paasschen, J., Evans, S. J., Parkinson, C., Woods, R. T., and Linden, D. E. J. (2009). Goal-oriented cognitive rehabilitation for an individual with mild cognitive impairment: behavioural and neuroimaging outcomes. Neurocase 15, 318-331. doi: 10.1080/13554790902783116

Clément, F., and Belleville, S. (2009). Test-retest reliability of fMRI verbal episodic memory paradigms in healthy older adults and in persons with mild cognitive impairment. Hum. Brain Mapp. 30, 4033-4047. doi: 10.1002/hbm.20827

Clément, F., Gauthier, S., and Belleville, S. (2013). Executive functions in mild cognitive impairment: emergence and breakdown of neural plasticity. Cortex 49 , 1268-1279. doi: 10.1016/j.cortex.2012.06.004

Dal Forno, G., Rasmusson, D. X., Brandt, J., Carson, K. A., Brookmeyer, R., Troncoso, J., et al. (1996). Apolipoprotein E genotype and rate of decline in probable Alzheimer's disease. Arch. Neurol. 53, 345-350. doi: 10.1001/archneur. 1996.00550040085017

Dannhauser, T. M., Walker, Z., Stevens, T., Lee, L., Seal, M., and Shergill, S. S. (2005). The functional anatomy of divided attention in amnestic mild cognitive impairment. Brain 128(Pt. 6), 1418-1427. doi: 10.1093/brain/awh413

de Villers-Sidani, E., Alzghoul, L., Zhou, X., Simpson, K. L., Lin, R. C., and Merzenich, M. M. (2010). Recovery of functional and structural age-related changes in the rat primary auditory cortex with operant training. Proc. Natl. Acad. Sci. U S A 107, 13900-13905. doi: 10.1073/pnas. 1007885107

Eickhoff, S. B., Laird, A. R., Grefkes, C., Wang, L. E., Zilles, K., and Fox, P. T. (2009). Coordinate-based activation likelihood estimation meta-analysis of 
neuroimaging data: a random-effects approach based on empirical estimates of spatial uncertainty. Hum. Brain Mapp. 30, 2907-2926. doi: 10.1002/hbm. 20718

Engvig, A., Fjell, A. M., Westlye, L. T., Moberget, T., Sundseth, O., Larsen, V. A., et al. (2010). Effects of memory training on cortical thickness in the elderly. Neuroimage 52, 1667-1676. doi: 10.1016/j.neuroimage.2010.05.041

Engvig, A., Fjell, A. M., Westlye, L. T., Moberget, T., Sundseth, O., Larsen, V. A., et al. (2012a). Memory training impacts short-term changes in aging white matter: a longitudinal diffusion tensor imaging study. Hum. Brain Mapp. 33, 2390-2406. doi: 10.1002/hbm.21370

Engvig, A., Fjell, A. M., Westlye, L. T., Skaane, N. V., Dale, A. M., Holland, D., et al. (2014). Effects of cognitive training on gray matter volumes in memory clinic patients with subjective memory impairment. J. Alzheimers Dis. 41, 779-791. doi: 10.3233/JAD-131889

Engvig, A., Fjell, A. M., Westlye, L. T., Skaane, N. V., Sundseth, O., and Walhovd, K. B. (2012b). Hippocampal subfield volumes correlate with memory training benefit in subjective memory impairment. Neuroimage 61, 188-194. doi: 10 . 1016/j.neuroimage.2012.02.072

Erickson, K. I., Colcombe, S. J., Wadhwa, R., Bherer, L., Peterson, M. S., Scalf, P. E., et al. (2007). Training-induced plasticity in older adults: effects of training on hemispheric asymmetry. Neurobiol. Aging 28, 272-283. doi: 10.1016/j. neurobiolaging.2005.12.012

Filippi, M., and Agosta, F. (2011). Structural and functional network connectivity breakdown in Alzheimer's disease studied with magnetic resonance imaging techniques. J. Alzheimers Dis. 24, 455-474. doi: 10.3233/JAD-2011101854

Forster, S., Buschert, V. C., Buchholz, H. G., Teipel, S. J., Friese, U., Zach, C., et al. (2011). Effects of a 6-month cognitive intervention program on brain metabolism in amnestic mild cognitive impairment and mild Alzheimer's disease. J. Alzheimers Dis. 25, 695-706. doi: 10.3233/JAD-2011-100996

Friston, K. J. (2011). Functional and effective connectivity: a review. Brain Connect. 1, 13-36. doi: 10.1089/brain.2011.0008

Gagnon, L. G., and Belleville, S. (2012). Training of attentional control in mild cognitive impairment with executive deficits: results from a double-blind randomised controlled study. Neuropsychol. Rehabil. 22, 809-835. doi: 10. 1080/09602011.2012.691044

Gaitán, A., Garolera, M., Cerulla, N., Chico, G., Rodriguez-Querol, M., and CanelaSoler, J. (2013). Efficacy of an adjunctive computer-based cognitive training program in amnestic mild cognitive impairment and Alzheimer's disease: a single-blind, randomized clinical trial. Int. J. Geriatr. Psychiatry 28, 91-99. doi: 10.1002 /gps.3794

Gates, N., and Valenzuela, M. (2010). Cognitive exercise and its role in cognitive function in older adults. Curr. Psychiatry Rep. 12, 20-27. doi: 10.1007/s11920009-0085-y

Geroldi, C., Pihlajamaki, M., Laakso, M. P., DeCarli, C., Beltramello, A., Bianchetti, A., et al. (1999). APOE-epsilon4 is associated with less frontal and more medial temporal lobe atrophy in AD. Neurology 53, 1825-1832. doi: 10.1212/wnl.53.8. 1825

Gomez-Ramirez, J., and Wu, J. (2014). Network-based biomarkers in Alzheimer's disease: review and future directions. Front. Aging Neurosci. 6:12. doi: 10 . 3389/fnagi.2014.00012

Goveas, J. S., Xie, C., Ward, B. D., Wu, Z., Li, W., Franczak, M., et al. (2011). Recovery of hippocampal network connectivity correlates with cognitive improvement in mild Alzheimer's disease patients treated with donepezil assessed by resting-state fMRI. J. Magn. Reson. Imaging 34, 764-773. doi: 10.1002/jmri. 22662

Green, C. S., and Bavelier, D. (2008). Exercising your brain: a review of human brain plasticity and training-induced learning. Psychol. Aging 23, 692-701. doi: 10. 1037/a0014345

Greenaway, M. C., Duncan, N. L., and Smith, G. E. (2013). The memory support system for mild cognitive impairment: randomized trial of a cognitive rehabilitation intervention. Int. J. Geriatr. Psychiatry 28, 402-409. doi: 10.1002/gps. 3838

Hampel, H., Wilcock, G., Andrieu, S., Aisen, P., Blennow, K., Broich, K., et al. (2011). Biomarkers for Alzheimer's disease therapeutic trials. Prog. Neurobiol. 95, 579-593. doi: 10.1016/j.pneurobio.2010.11.005

Hampstead, B. M., Stringer, A. Y., Stilla, R. F., Deshpande, G., Hu, X., Moore, A. B., et al. (2011). Activation and effective connectivity changes following explicit-memory training for face-name pairs in patients with mild cognitive impairment: a pilot study. Neurorehabil. Neural Repair 25, 210-222. doi: 10. $1177 / 1545968310382424$

Hampstead, B. M., Stringer, A. Y., Stilla, R. F., Giddens, M., and Sathian, K. (2012). Mnemonic strategy training partially restores hippocampal activity in patients with mild cognitive impairment. Hippocampus 22, 1652-1658. doi: 10. 1002/hipo. 22006

He, Y., Chen, Z. J., and Evans, A. C. (2007). Small-world anatomical networks in the human brain revealed by cortical thickness from MRI. Cereb. Cortex 17, 24072419. doi: 10.1093/cercor/bhl149

He, Y., Chen, Z., and Evans, A. (2008). Structural insights into aberrant topological patterns of large-scale cortical networks in Alzheimer's disease. J. Neurosci. 28, 4756-4766. doi: 10.1523/JNEUROSCI.0141-08.2008

He, Y., Chen, Z., Gong, G., and Evans, A. (2009). Neuronal networks in Alzheimer's disease. Neuroscientist 15, 333-350. doi: 10.1177/1073858409334423

Herrera, C., Chambon, C., Michel, B. F., Paban, V., and Alescio-Lautier, B. (2012). Positive effects of computer-based cognitive training in adults with mild cognitive impairment. Neuropsychologia 50, 1871-1881. doi: 10.1016/j. neuropsychologia.2012.04.012

Hoeft, F., McCandliss, B. D., Black, J. M., Gantman, A., Zakerani, N., Hulme, C., et al. (2011). Neural systems predicting long-term outcome in dyslexia. Proc. Natl. Acad. Sci. U S A 108, 361-366. doi: 10.1073/pnas.1008950108

Hosseini, S. M., Black, J. M., Soriano, T., Bugescu, N., Martinez, R., Raman, M. M., et al. (2013). Topological properties of large-scale structural brain networks in children with familial risk for reading difficulties. Neuroimage 71, 260-274. doi: 10.1016/j.neuroimage.2013.01.013

Hosseini, S. M., and Kesler, S. R. (2013). Comparing connectivity pattern and small-world organization between structural correlation and resting-state networks in healthy adults. Neuroimage 78C, 402-414. doi: 10.1016/j.neuroimage. 2013.04.032

James, B. D., Leurgans, S. E., Hebert, L. E., Scherr, P. A., Yaffe, K., and Bennett, D. A. (2014). Contribution of Alzheimer disease to mortality in the United States. Neurology 82, 1045-1050. doi: 10.1212/WNL.0000000000000240

Jessen, F., Wiese, B., Bachmann, C., Eifflaender-Gorfer, S., Haller, F., Kolsch, H., et al. (2010). Prediction of dementia by subjective memory impairment: effects of severity and temporal association with cognitive impairment. Arch. Gen. Psychiatry 67, 414-422. doi: 10.1001/archgenpsychiatry.2010.30

Johnson, J. K., Gross, A. L., Pa, J., McLaren, D. G., Park, L. Q., Manly, J. J., et al. (2012). Longitudinal change in neuropsychological performance using latent growth models: a study of mild cognitive impairment. Brain Imaging Behav. 6, 540-550. doi: 10.1007/s11682-012-9161-8

Kelly, A. M., Hester, R., Foxe, J. J., Shpaner, M., and Garavan, H. (2006a). Flexible cognitive control: effects of individual differences and brief practice on a complex cognitive task. Neuroimage 31, 866-886. doi: 10.1016/j.neuroimage. 2006.01.008

Kelly, C., Foxe, J. J., and Garavan, H. (2006b). Patterns of normal human brain plasticity after practice and their implications for neurorehabilitation. Arch. Phys. Med. Rehabil. 87(12 Suppl. 2), S20-S29. doi: 10.1016/j.apmr.2006.08.333

Kinsella, G. J., Mullaly, E., Rand, E., Ong, B., Burton, C., Price, S., et al. (2009). Early intervention for mild cognitive impairment: a randomised controlled trial. J. Neurol. Neurosurg. Psychiatry 80, 730-736. doi: 10.1136/jnnp.2008.148346

Koch, W., Teipel, S., Mueller, S., Benninghoff, J., Wagner, M., Bokde, A. L., et al. (2012). Diagnostic power of default mode network resting state fMRI in the detection of Alzheimer's disease. Neurobiol. Aging 33, 466-478. doi: 10.1016/j. neurobiolaging.2010.04.013

Koush, Y., Rosa, M. J., Robineau, F., Heinen, K., Rieger, S. W., Weiskopf, N., et al. (2013). Connectivity-based neurofeedback: dynamic causal modeling for realtime fMRI. Neuroimage 81, 422-430. doi: 10.1016/j.neuroimage.2013.05.010

Li, W., Antuono, P. G., Xie, C., Chen, G., Jones, J. L., Ward, B. D., et al. (2012). Changes in regional cerebral blood flow and functional connectivity in the cholinergic pathway associated with cognitive performance in subjects with mild Alzheimer's disease after 12-week donepezil treatment. Neuroimage 60, 10831091. doi: 10.1016/j.neuroimage.2011.12.077

Li, H., Li, J., Li, N., Li, B., Wang, P., and Zhou, T. (2011). Cognitive intervention for persons with mild cognitive impairment: a meta-analysis. Ageing Res. Rev. 10, 285-296. doi: 10.1016/j.arr.2010.11.003

Lim, H. K., Jung, W. S., and Aizenstein, H. J. (2013). Aberrant topographical organization in gray matter structural network in late life depression: a graph theoretical analysis. Int. Psychogeriatr. 25, 1929-1940. doi: 10.1017/S1041610213 00149X 
Lindesay, J., Bullock, R., Daniels, H., Emre, M., Forstl, H., Frolich, L., et al. (2010). Turning principles into practice in Alzheimer's disease. Int. J. Clin. Pract. 64, 1198-1209. doi: 10.1111/j.1742-1241.2010.02417.x

Lorenzi, M., Beltramello, A., Mercuri, N. B., Canu, E., Zoccatelli, G., Pizzini, F. B., et al. (2011). Effect of memantine on resting state default mode network activity in Alzheimer's disease. Drugs Aging 28, 205-217. doi: 10.2165/11586440000000000-00000

Lövdén, M., Bodammer, N. C., Kühn, S., Kaufmann, J., Schütze, H., Tempelmann, C., et al. (2010). Experience-dependent plasticity of white-matter microstructure extends into old age. Neuropsychologia 48, 3878-3883. doi: 10.1016/j. neuropsychologia.2010.08.026

Lövdén, M., Schaefer, S., Noack, H., Bodammer, N. C., Kühn, S., Heinze, H.-J., et al. (2012). Spatial navigation training protects the hippocampus against age-related changes during early and late adulthood. Neurobiol. Aging 33, 620.e9-620.e22. doi: 10.1016/j.neurobiolaging.2011.02.013

Martins, C. A., Oulhaj, A., de Jager, C. A., and Williams, J. H. (2005). APOE alleles predict the rate of cognitive decline in Alzheimer disease: a nonlinear model. Neurology 65, 1888-1893. doi: 10.1212/01.wnl.0000188871.74093.12

McDowell, I., Xi, G., Lindsay, J., and Tierney, M. (2007). Mapping the connections between education and dementia. J. Clin. Exp. Neuropsychol. 29, 127-141. doi: 10.1080/13803390600582420

McLaren, D. G., Ries, M. L., Xu, G., and Johnson, S. C. (2012). A generalized form of context-dependent psychophysiological interactions (gPPI): a comparison to standard approaches. Neuroimage 61, 1277-1286. doi: 10.1016/j.neuroimage. 2012.03.068

Meng, X., and D'Arcy, C. (2012). Education and dementia in the context of the cognitive reserve hypothesis: a systematic review with meta-analyses and qualitative analyses. PLoS One 7:e38268. doi: 10.1371/journal.pone.0038268

Moro, V., Condoleo, M. T., Sala, F., Pernigo, S., Moretto, G., and Gambina, G. (2012). Cognitive stimulation in a-MCI: an experimental study. Am. J. Alzheimers Dis. Other Demen. 27, 121-130. doi: 10.1177/1533317512441386

Mozolic, J. L., Hayasaka, S., and Laurienti, P. J. (2010). A cognitive training intervention increases resting cerebral blood flow in healthy older adults. Front. Hum. Neurosci. 4:16. doi: 10.3389/neuro.09.016.2010

Murphy, S. L., Xu, J., and Kochanek, K. D. (2013). Deaths: final data for 2010. Natl. Vital Stat. Rep. 61, 1-117.

Nagata, T., Shinagawa, S., Ochiai, Y., Aoki, R., Kasahara, H., Nukariya, K., et al. (2011). Association between executive dysfunction and hippocampal volume in Alzheimer's disease. Int. Psychogeriatr. 23, 764-771. doi: 10. 1017/S1041610210002164

Nyberg, L., Sandblom, J., Jones, S., Neely, A. S., Petersson, K. M., Ingvar, M., et al. (2003). Neural correlates of training-related memory improvement in adulthood and aging. Proc. Natl. Acad. Sci. U S A 100, 13728-13733. doi: 10. 1073/pnas.1735487100

Ohm, T. G., Kirca, M., Bohl, J., Scharnagl, H., Gross, W., and Marz, W. (1995). Apolipoprotein E polymorphism influences not only cerebral senile plaque load but also Alzheimer-type neurofibrillary tangle formation. Neuroscience 66, 583587. doi: 10.1016/0306-4522(94)00596-w

O'Reilly, J. X., Woolrich, M. W., Behrens, T. E., Smith, S. M., and JohansenBerg, H. (2012). Tools of the trade: psychophysiological interactions and functional connectivity. Soc. Cogn. Affect. Neurosci. 7, 604-609. doi: 10.1093/scan/ nss055

Orrù, G., Pettersson-Yeo, W., Marquand, A. F., Sartori, G., and Mechelli, A. (2012). Using support vector machine to identify imaging biomarkers of neurological and psychiatric disease: a critical review. Neurosci. Biobehav. Rev. 36, 1140-1152. doi: 10.1016/j.neubiorev.2012.01.004

Park, D. C., and Bischof, G. N. (2013). The aging mind: neuroplasticity in response to cognitive training. Dialogues Clin. Neurosci. 15, 109-119.

Parks, C. M., Iosif, A. M., Farias, S., Reed, B., Mungas, D., and DeCarli, C. (2011). Executive function mediates effects of white matter hyperintensities on episodic memory. Neuropsychologia 49, 2817-2824. doi: 10.1016/j.neuropsychologia. 2011.06.003

Peleg-Raibstein, D., Pezze, M. A., Ferger, B., Zhang, W. N., Murphy, C. A., Feldon, J., et al. (2005). Activation of dopaminergic neurotransmission in the medial prefrontal cortex by N-methyl-d-aspartate stimulation of the ventral hippocampus in rats. Neuroscience 132, 219-232. doi: 10.1016/j.neuroscience.2004.12.016

Prince, M., Prina, M., and Guerchet, M. (2013). "Journey of caring: an analysis of long-term care for dementia," in World Alzheimer Report 2013 (London: Alzheimer's Disease International), 1-92.
Putcha, D., O’Keefe, K., LaViolette, P., O’Brien, J., Greve, D., Rentz, D. M., et al. (2011). Reliability of functional magnetic resonance imaging associative encoding memory paradigms in non-demented elderly adults. Hum. Brain Mapp. 32, 2027-2044. doi: 10.1002/hbm.21166

Radanovic, M., Pereira, F. R., Stella, F., Aprahamian, I., Ferreira, L. K., Forlenza, O. V., et al. (2013). White matter abnormalities associated with Alzheimer's disease and mild cognitive impairment: a critical review of MRI studies. Expert. Rev. Neurother. 13, 483-493. doi: 10.1586/ern.13.45

Rainville, C., Lepage, E., Gauthier, S., Kergoat, M. J., and Belleville, S. (2012). Executive function deficits in persons with mild cognitive impairment: a study with a Tower of London task. J. Clin. Exp. Neuropsychol. 34, 306-324. doi: 10. 1080/13803395.2011.639298

Ranganath, C., Cohen, M. X., and Brozinsky, C. J. (2005). Working memory maintenance contributes to long-term memory formation: neural and behavioral evidence. J. Cogn. Neurosci. 17, 994-1010. doi: 10.1162/08989290544 75118

Rebok, G. W., Ball, K., Guey, L. T., Jones, R. N., Kim, H. Y., King, J. W., et al. (2014). Ten-year effects of the advanced cognitive training for independent and vital elderly cognitive training trial on cognition and everyday functioning in older adults. J. Am. Geriatr. Soc. 62, 16-24. doi: 10.1111/jgs.12607

Reijnders, J., van Heugten, C., and van Boxtel, M. (2013). Cognitive interventions in healthy older adults and people with mild cognitive impairment: a systematic review. Ageing Res. Rev. 12, 263-275. doi: 10.1016/j.arr.2012.07.003

Risacher, S. L., and Saykin, A. J. (2013). Neuroimaging and other biomarkers for Alzheimer's disease: the changing landscape of early detection. Annu. Rev. Clin. Psychol. 9, 621-648. doi: 10.1146/annurev-clinpsy-050212-185535

Roe, C. M., Xiong, C., Miller, J. P., and Morris, J. C. (2007). Education and Alzheimer disease without dementia: support for the cognitive reserve hypothesis. Neurology 68, 223-228. doi: 10.1212/01.wnl.0000251303.50459.8a

Rosen, H. J., Kramer, J. H., Gorno-Tempini, M. L., Schuff, N., Weiner, M., and Miller, B. L. (2002). Patterns of cerebral atrophy in primary progressive aphasia. Am. J. Geriatr. Psychiatry 10, 89-97. doi: 10.1097/00019442-20020100000011

Rosen, A. C., Sugiura, L., Kramer, J. H., Whitfield-Gabrieli, S., and Gabrieli, J. D. (2011). Cognitive training changes hippocampal function in mild cognitive impairment: a pilot study. J. Alzheimers Dis. 26, 349-357. doi: 10.3233/JAD2011-0009

Rovner, B. W., Casten, R. J., Hegel, M. T., and Leiby, B. E. (2012). Preventing cognitive decline in older African Americans with mild cognitive impairment: design and methods of a randomized clinical trial. Contemp. Clin. Trials 33, 712720. doi: 10.1016/j.cct.2012.02.016

Rudebeck, S. R., Bor, D., Ormond, A., O'Reilly, J. X., and Lee, A. C. (2012). A potential spatial working memory training task to improve both episodic memory and fluid intelligence. PLoS One 7:e50431. doi: 10.1371/journal.pone. 0050431

Scarpazza, C., Sartori, G., De Simone, M. S., and Mechelli, A. (2013). When the single matters more than the group: very high false positive rates in single case voxel based morphometry. Neuroimage 70, 175-188. doi: 10.1016/j.neuroimage. 2012.12.045

Seeley, W. W., Crawford, R. K., Zhou, J., Miller, B. L., and Greicius, M. D. (2009). Neurodegenerative diseases target large-scale human brain networks. Neuron 62, 42-52. doi: 10.1016/j.neuron.2009.03.024

Sehm, B., Frisch, S., Thone-Otto, A., Horstmann, A., Villringer, A., and Obrig, H. (2011). Focal retrograde amnesia: voxel-based morphometry findings in a case without MRI lesions. PLoS One 6:e26538. doi: 10.1371/journal.pone.0026538

Sheline, Y. I., Morris, J. C., Snyder, A. Z., Price, J. L., Yan, Z., D’Angelo, G., et al. (2010). APOE4 allele disrupts resting state fMRI connectivity in the absence of amyloid plaques or decreased CSF A $\beta 42$. J. Neurosci. 30, 17035-17040. doi: 10. 1523/JNEUROSCI.3987-10.2010

Singh, M. K., Kesler, S. R., Hadi Hosseini, S. M., Kelley, R. G., Amatya, D., Hamilton, J. P., et al. (2013). Anomalous gray matter structural networks in major depressive disorder. Biol. Psychiatry 74, 777-785. doi: 10.1016/j.biopsych. 2013.03.005

Spironelli, C., Bergamaschi, S., Mondini, S., Villani, D., and Angrilli, A. (2013). Functional plasticity in Alzheimer's disease: effect of cognitive training on language-related ERP components. Neuropsychologia 51, 1638-1648. doi: 10. 1016/j.neuropsychologia.2013.05.007

Stern, Y. (2006). Cognitive reserve and Alzheimer disease. Alzheimer Dis. Assoc. Disord. 20(3 Suppl. 2), S69-S74. doi: 10.1097/01.wad.0000213815.20177.19 
Tzourio-Mazoyer, N., Landeau, B., Papathanassiou, D., Crivello, F., Etard, O., Delcroix, N., et al. (2002). Automated anatomical labeling of activations in SPM using a macroscopic anatomical parcellation of the MNI MRI single-subject brain. Neuroimage 15, 273-289. doi: 10.1006/nimg.2001. 0978

Valdes, E. G., O'Connor, M. L., and Edwards, J. D. (2012). The effects of cognitive speed of processing training among older adults with psychometricallydefined mild cognitive impairment. Curr. Alzheimer Res. 9, 999-1009. doi: 10. 2174/156720512803568984

van Paasschen, J., Clare, L., Woods, R. T., and Linden, D. E. J. (2009). Can we change brain functioning with cognition-focused interventions in Alzheimer's disease? The role of functional neuroimaging. Restor. Neurol. Neurosci. 27, 473491. doi: 10.3233/RNN-2009-0494

Wang, L., Brier, M. R., Snyder, A. Z., Thomas, J. B., Fagan, A. M., Xiong, C., et al. (2013). Cerebrospinal fluid A $\beta 42$, phosphorylated Tau181, and resting-state functional connectivity. JAMA Neurol. 70, 1242-1248. doi: 10.1001/jamaneurol. 2013.3253

Yao, Z., Zhang, Y., Lin, L., Zhou, Y., Xu, C., and Jiang, T. (2010). Abnormal cortical networks in mild cognitive impairment and Alzheimer's disease. PLoS Comput. Biol. 6:e1001006. doi: 10.1371/journal.pcbi.1001006

Yetkin, F. Z., Rosenberg, R. N., Weiner, M. F., Purdy, P. D., and Cullum, C. M. (2006). FMRI of working memory in patients with mild cognitive impairment and probable Alzheimer's disease. Eur. Radiol. 16, 193-206. doi: 10.1007/s00330005-2794-x
Zahn, R., Buechert, M., Overmans, J., Talazko, J., Specht, K., Ko, C. W., et al. (2005). Mapping of temporal and parietal cortex in progressive nonfluent aphasia and Alzheimer's disease using chemical shift imaging, voxel-based morphometry and positron emission tomography. Psychiatry Res. 140, 115-131. doi: 10.1016/j. pscychresns.2005.08.001

Zatorre, R. J., Fields, R. D., and Johansen-Berg, H. (2012). Plasticity in gray and white: neuroimaging changes in brain structure during learning. Nat. Neurosci. 15, 528-536. doi: 10.1038/nn.3045

Conflict of Interest Statement: The authors declare that the research was conducted in the absence of any commercial or financial relationships that could be construed as a potential conflict of interest.

Received: 28 May 2014; accepted: 11 August 2014; published online: 26 August 2014. Citation: Hosseini SMH, Kramer JH and Kesler SR (2014) Neural correlates of cognitive intervention in persons at risk of developing Alzheimer's disease. Front. Aging Neurosci. 6:231. doi: 10.3389/fnagi.2014.00231

This article was submitted to the journal Frontiers in Aging Neuroscience.

Copyright (C) 2014 Hosseini, Kramer and Kesler. This is an open-access article distributed under the terms of the Creative Commons Attribution License (CC BY). The use, distribution or reproduction in other forums is permitted, provided the original author(s) or licensor are credited and that the original publication in this journal is cited, in accordance with accepted academic practice. No use, distribution or reproduction is permitted which does not comply with these terms. 